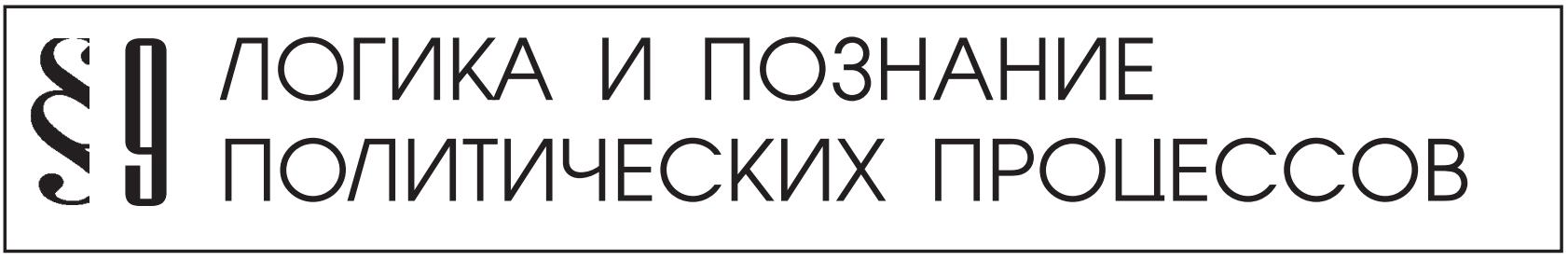

Шмидт Т.H.

\title{
ТЕОРЕТИКО-ПРАВОВОЕ ОБОСНОВАНИЕ ЧРЕЗВЫЧАЙНОГО ПРАВОВОГО РЕГУЛИРОВАНИЯ И ДОКТРИНА «ИСКЛЮЧИТЕЛЬНОГО ПОЛОЖЕНИЯ»
}

\begin{abstract}
Аннотация: В статье рассматривается проблема обоснования чрезвычайного правового регулирования. Показывается как опасность перехода от чрезвычайного положения к авторитарной власти диктатора, так и неизбежность правового регулирования в экстремальных ситуациях дл обеспечения безопасности общества. Для обоснования необходимости чрезвычайного правового регулирования анализируется доктрина «исключительного положения».Автор делает вывод о том, что чрезвычайное правовое регулирование является обоснованной исключительной мерой для преодоления возникших для безопасности общества и государства угроз. Конечно, само чрезвычайное право в своей основе есть нарушение ординарного законодательства и может быть квалифицирована как правонарушение. Но, право на правонарушение чрезвычайной ситуачии - вынужденное зло, дающее основу для восстановления порядка и безопасности общества. В этом отношении чрезвычайное правовое регулирование сродни таким институтам как необходимая оборона, крайняя необходимость, обоснованный риск.Во всех этих случаях речь идет об исключении из общих правил ради более высокой ценности. Но, при этом всегда сохраняется риск выхода за пределы предоставленных возможностей и полномочий и совершение правонарушения. Но, без такого риска невозможно гарантировать сохранение более высоких ценностей, чем формальное соблюдение закона.
\end{abstract}

Review: The article is devoted to the grounds for emergency legal regulation. The author shows both the danger of transition from emergency situation to dictator's authoritarian power and a necessity of legal regulation in extreme situations in order to provide social security. To provide grounds for emergency legal regulation, the author analyzes the 'state of emergency' doctrine. The author concludes that emergency legal regulation is a reasonable exceptional measure to overcome social and state security threats. Of course, the emergency law itself is, basically, the violation of ordinary legislation so it can be qualified as a violation of law. On the other hand, the right to commit a violation in an emergency situation is a 'necessary evil' creating grounds for restoring order and social security. In this respect, emergency legal regulation is similar to such institutions as the right of self-defense, necessity and reasonable risk. All these cases refer to the exclusion from general rules for the sake of a higher value. At the same time, there is always a risk to go beyond the limits of provided responsibilities and powers and commit a violation. But without such a risk, it would be impossible to guarantee the preservation of values higher than a formal observation of law.

Ключевые слова: чрезвычайное правовое регулирование, чрезвычайная ситуация, чрезвычайное право, исключительное положение, экстраординарное правовое регулирование, чрезвычайные полномочия, кризисная теория, чрезвычайный правовой режим, чрезвычайное законодательство, нарушение гражданских прав Keywords: emergency legal regulation, emergency situation, emergency law, state of emergency, extraordinary legal regulation, emergency powers, theory of crisis, emergency legal regime, emergency legislation, violation of civil rights.

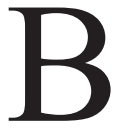

современной юридической науке практически не дискутируется вопрос о допустимости чрезвычайного правового регулирования как такового. Существование чрезвычайного законодательства рассматривается как нечто естественное и привычное. Однако, вполне резонными для теоретико-правового дискурса являются вопросы: 
- возможно ли и в какой степени допустимо правовое регулирование в чрезвычайных обстоятельствах;

- каковы регулятивные возможности права в условиях чрезвычайной обстановки;

- каковы пределы и условия чрезвычайного правового регулирования.

Без решения этих теоретических вопросов невозможно сконструировать концепцию и модель чрезвычайного правового регулирования, обеспечить научную основу для разработки, принятия и применения норм чрезвычайного права.

Во-первых, закономерен вопрос об использовании правовых средств для преодоления экстремальных ситуаций. Право как социальный регулятор обладает такими качествами как нормативность и общеобязательность ${ }^{1}$. В правовых нормах отражаются типичные, повторяющиеся отношения. Право - есть результат отражения, закрепления и охраны нормальных отношений ${ }^{2}$. Как справедливо отмечал римский юрист «право не касается того, что случается один раз или два». В целом для права характерны стандартизация, обобщенность, абстрактный характер, регулирование не конкретного общественного отношения, а вида общественных отношений, отличающегося повторяемостью, типичностью.

Учет индивидуальных особенностей нетипичных правовых ситуаций возможен на стадии индивидуального правового регулирования и в процессе применения права, когда все такие нюансы можно принять во внимание при принятии индивидуального акта или восполнения пробела в законе. Так, заранее невозможно определить меру наказания для правонарушителя, размер алиментов на содержание члена семьи и т.п. юридические моменты, индивидуальные для каждого юридического казуса. На такие случаи в позитивном праве закреплены положения, позволяющие правоприменителю принимать решения по конкретным юридическим делам на основе усмотрения и учета

\footnotetext{
${ }^{1}$ См: Лейст О.Э. Сущность права. Проблемы теории и философии права.- М.: Зерцало, 2008. 352 с.; Байтин М.И. Сущность права (современное нормативное правопонимание на грани двух веков). - Саратов.: СГАП, 2001. 416 с.; Сорокин В.В. Понятие и сущность права в русской духовной культуре. - М.: Юрлитинформ, 2007.

${ }^{2}$ Кудрявцев В.Н. Правовое поведение: норма и патология. М.: Наука, 1982. 287 c.
}

конкретных жизненных обстоятельств. Широко в законодательстве используются исключения из общих правил, создавая тем самым правовую основу для разрешения нестандартных дел в альтернативном порядке.

По своей природе чрезвычайные ситуации относятся к исключительным и нетипичным, иногда редким и неповторимым явлениям. Ставя вопрос о допустимости общих правовых норм для урегулирования отношений в чрезвычайных обстоятельствах, нужно иметь в виду, что:

- как правило, заранее спрогнозировать и определить характер и протекание чрезвычайной ситуации практически невозможно;

- чрезвычайные ситуации - исключительные обстоятельства, выходящие за пределы нормальной жизни общества, порождающие новые и ранее неизвестные отношения и социальные последствия;

- выход из кризисной ситуации и преодоление возникших последствий зачастую носят индивидуальный характер и заранее не могут быть с точностью до всех деталей просчитаны и запланированы.

При соотношении права как социального регулятора, рассчитанного на нормальное течение жизни, и чрезвычайной ситуации как исключительного и ненормального, выходящего за привычные границы, явления, может показаться, что право бессильно и непродуктивно в таких обстоятельствах. Ликвидация чрезвычайной ситуации при бессилии права может быть обеспечена лишь путем предоставления дискреционных полномочий органам государственной власти, которые в экстренной ситуации будут исходить не из закона, а из внеправовых мотивов и пользоваться голой силой принуждения.

При таком взгляде роль закона будет ограничена общей санкцией на право государства самостоятельно искать решение в чрезвычайной ситуации. Лишь индивидуальное правовое регулирование может быть здесь полезным, да и то в форме саморегулирования, поскольку для правоприменения необходима общая буква закона. Закона же для конкретной чрезвычайной ситуации быть не может. В самой идеальной юридической норме невозможно предусмотреть все индивидуальные случаи жизни. При любой степени конкретности норма права не перестает быть общим и абстрактным правилом, рассчитанным на повторяющиеся общественные отношения и случаи. Трудно спорить с позицией А. Матио, замечавшего, что «нельзя на- 


\section{Политика и общество 9 (105) • 2013}

перед с точностью определить, какими будут чрезвычайные обстоятельства и в какие последствия для страны выльются»³.

При еще более радикальном подходе вовсе отрицается допустимость юридического санкционирования деятельности правительства в чрезвычайных обстоятельствах как нарушение принципов правовой государственности и потенциальная основа для перехода к тиранической и деспотической власти.

Так, в дореволюционной правовой мысли ярким представителем критического направления в отношении к чрезвычайному законодательству был Я.М. Магазинер. Он прямо рассматривал наличие законов об исключительном положении, а также введение особых мер охраны порядка и безопасности с ограничением прав человека, как проявление силы, а не авторитета власти и закона. За исключительным законодательством фактически стоит произвол государственной администрации и бесправие. Он даже объяснял революцию в России как восстание против вырождения права в произвол. Опасаясь вырождения чрезвычайного законодательства в репрессивный механизм подавления свободы, он возражал против принятия особого закона об исключительном положении.

По словам Я.М. Магазинера «великий перелом в исторических судьбах России, связанный навеки с исторической датой 17 октября, ценой неисчислимых и тяжелых жертв, создал для России возможность мирной эволюции, прогрессивного развития неисчерпаемых богатств народного духа. И величайшая опасность, грозящая новыми потрясениями воскресшей стране, заключается в перерождении ее нового, еще неокрепшего права. Таким перерождением является исключительное положение, режим произвола и бесправия. Его продолжительное господство уже ввергло однажды в кровавую анархию страну. Остережемся от повторения роковых, непоправимых ошибок; будем помнить, что в господстве права - и только в нем - залог возрождения испытанной многими и великими бедствиями России» ${ }^{4}$

В качестве весьма весомого аргумента приводятся исторические факты, когда под видом чрез-

\footnotetext{
${ }^{3}$ Матио А. Теория чрезвычайных обстоятельств. - М., 1992. C. 192 .

${ }^{4}$ Магазинер Я.М. Чрезвычайно-указное право в России. М., 1911. C. 170 .
}

вычайной ситуации и с санкции закона власть переходила в руки авторитарных лидеров, а в обществе начиналась гражданская война, революция или устанавливался тоталитарный режим. Наиболее ярким примером является нацистская Германия. 23 марта 1933 г. был принят рейхстагом и одобрен Президентом Гинденбургом Закон о преодолении бедственного положения народа и государства (Закон о чрезвычайных полномочиях). Закон был принят под прямым давлением НСДАП и лично главы Правительства Адольфа Гитлера. А. Гитлер убедил Президента Гинденбурга, что в сложившейся ситуации политического кризиса необходимо ограничить конституционный права и свободы и передать исключительные полномочия правительству во главе с Гитлером. До принятия закона был распущен рейхстаг, начались репрессии против коммунистов.

Принятый закон о чрезвычайных полномочиях состоял всего из пяти статей, которые вводили следующие правила:

- правительство получило право на издание законов;

- издаваемые правительством законы могли противоречить требованиям Веймарской конституции;

- давали правительству неограниченные права в сфере внешней политики;

- первоначально ограничивали срок полномочий правительства 3 годами, но продлевались вплоть до падения гитлеровской Германии.

Фактически данный закон окончательно привел к ликвидации демократических институтов власти в Германии, создал юридическую основу для формирования тоталитарного режима нацистов и стал частью одной из самых опасных гуманитарных катастроф XX века - второй мировой войны ${ }^{5}$. В приведенном примере переход к чрезвычайному положению, а затем и диктатуре нацистов происходил в строгом соответствии с законом и юридической процедурой. Веймарская конституция позволяла отступить от ее положений при том условии, что в рейхстаге будет набрано более 2/3 голосов депутатов за такой противоконституционный закон. Все юридические условия при принятии названного закона были соблюдены, что доказывает то, что ни одно го-

${ }^{5}$ Марченко М.Н. Источники права. - М.: Проспект, 2001. C. 221. 
сударство с самым совершенным законодательством не застраховано от того, что, не нарушая закон и демократические процедуры, может быть установлен античеловеческий и антиправовой режим.

При такой логике, когда недопустимо в законе давать дискреционные полномочия государству в условиях чрезвычайной ситуации, не только обесценивается роль права, но и расширяется возможность для произвола власти, узурпации полномочий и использования силовых факторов разрешения кризисов.

Приведенная точка зрения при своей убедительности, все-таки не учитывает ряд соображений:

во-первых, чрезвычайные ситуации - весьма распространенные явления и очень часто повторяются, особенно когда речь идет о природных катаклизмах;

во-вторых, соответственно, в определенной мере возможно предвидение чрезвычайных ситуаций и создание моделей по выходу из них;

в-третьих, внеправовой механизм преодоления экстремальных ситуаций опасен произволом власти, возможностью завуалированного переворота и захвата власти;

в-четвертых, наличие четкой юридической базы для деятельности органов государственной власти в чрезвычайной ситуации превращает чрезвычайное правовое регулирование в гарант и средство защиты прав и свобод граждан, мощный фактор недопущения скатывания политического режима в авторитаризм или тоталитаризм, основанных на голой силе, а не на законе.

Проблема возможности и допустимости чрезвычайного права тесно связана с вопросом об управляемости общественными процессами в условиях кризисов и переходных состояний. При экстремальной ситуации сужаются возможности не только права, но и государственной власти повлиять на стабилизацию возникших общественных отношений. Мировая история знает множество случаев, когда кризисы приводили к хаосу, гражданским войнам, переворотам, революциям и восстаниям, а власть оказывалась неэффективным инструментов разрешения возникшей ситуации.

Однако, В.В. Сорокин убедительно доказал, что и в переходный период сохраняется управляемость и право имеет достаточный потенциал для упорядочения конфликтных отношений. Ученый утверждает: «переходное состояние общества не является неправовым, хотя в переходный период правовой порядок не является абсолютным в силу вероятностного характера развития правовой системы и возрастания в ней процессов дезорганизации... отмечая своеобразие признаков права в условиях переходности, представления о неизбежной в переходный период неполноценности права можно признать односторонними. Правовое регулирование в переходных условиях не знает перерывов и не заменяется полностью произволом реформаторских и иных социальных сил. Без права невозможно вернуть жизнь общества в нормальную колею, не говоря уже о создании новых социальных форм» ${ }^{6}$.

Причем степень эффективности властных институтов и позитивного права зависит от концептуальной основы и ценностных ориентаций власти и общества, авторитета и силы власти и закона в глазах общества. Именно чрезвычайное и переходное право играет очень существенную роль в оформлении перехода, сохранении порядка и установления стабильной основы для жизни общества. Неправовой характер перехода от одного строя к другому вполне обоснованно отвергается В.В. Сорокиным как разрушительный, опасный и не имеющий фактических доказательств. Напротив, при смене общественно-политического строя, реформаторы пытаются обеспечить преемственность с помощью опоры на закон, создание легальных основ для своей деятельности.

Конечно, утверждать, что государству и праву подконтрольны все отношения, возникающие в чрезвычайных условиях, нет никаких оснований. Даже при нормальном ходе общественного развития далеко не все отношения прогнозируются и подвергаются государственно-правовому воздействию. В чрезвычайных обстоятельствах степень беспорядка, хаоса в общественной жизни возрастает, а управленческий и регулятивный потенциал государственно-правовых институтов уменьшается. Но, это не означает, что государство и право оказываются неэффективными и излишними в таких условиях. Напротив, государственно-правовые механизмы и средства оказываются одними из наиболее востребованных в критических обстоятельствах, когда общество само не может справиться с

${ }^{6}$ Сорокин B.B. Теория государства и права переходного периода. - Барнаул.: ОАО «Алтайский полиграфический комбинат», 2007. С. $460-461$. 


\section{Политика и общество $9(105) \cdot 2013$}

экстремальными событиями и нуждается во внешней поддержке и организации.

Вообще, само появление государственности и права - есть результат экстремальных условий жизни человеческого сообщества. Согласно кризисной концепции, которая весьма доказательна, на известной ступени исторического развития суровые климатические условия привели к ограниченности ресурсов и поставили вопрос о выживании человечества. Именно, необходимость распределения ресурсов и задача по выживанию общества привели к появлению государства и права как средствам организации общества в критических условиях.

А.Б. Венгеров отмечал: «10-12 тыс. лет назад возникли экологические кризисные явления, которые, по мнению некоторых ученых, угрожали существованию человечества как биологического вида. Произошли неблагоприятные изменения климата, началось вымирание мегафауны (мамонтов, шерстистых носорогов и др.), бывшей основным источником питания человека в некоторых районах. Человечество ответило на эти кризисные явления переходом к новому способу существования и воспроизводства - к производящей экономике, произошла «неолитическая революция»7. Вслед за этими кризисными событиями возникает необходимость в возникновении государства для распределения ограниченных ресурсов, организации обороны от нападений, защиты населения от неурожаев, климатических катаклизмов и т.п.

Кризисная теория происхождения государственности является еще одним весомым доказательством того, что государственно-правовое регулирование в экстраординарных обстоятельствах, угрожающих безопасности общества, необходимо и возможно, понимая при этом что, заранее определить средства и пути преодоления кризиса практически невозможно. Но, и запрещать экстраординарные действия власти и закона в таких условиях недопустимо с точки зрения необходимости самосохранения общества. Иных путей по выходу из кризиса у общества, как правило, не оказывается.

\footnotetext{
${ }^{7}$ Венгеров А.Б. Теория государства и права. - М.: Юриспруденция, 2000. С.89.; Алексеев К. П., Першии А. И. История первобытного общества. М., 1990; Дробышевский С.А. Политическая организация общества и право как явления социальной эволюции. - Красноярск.: КрасГУ, 1995. 297 с.
}

Для обоснования необходимости чрезвычайных полномочий государства в экстремальных ситуациях на рубеже XIX - XX вв. стала формироваться доктрина «исключительного положения» ${ }^{8}$. По смыслу данной доктрины в обычных, нормальных условиях государство должно действовать в строгом соответствии с законом. Принципы правового государства, в том числе господство права и верховенство закона, являются нерушимыми для стабильного общества. В ситуации, когда обществу угрожают социальные или природные катастрофы и для водворения порядка недостаточно обычных средств управления на основе закона, тогда допускается использование государством экстраординарных мер, выходящих за пределы закона.

«Исключительное положение» является единственным основанием отступления от закона и принципов правового государства ради спасения общества и государства9. Государство получает карт-бланш только в качестве исключения и лишь для преодоления возникшего кризиса. В исключительном положении ординарное законодательство действует с ограничениями и изъятиями и, по сути, формируется новое «чрезвычайное право», чаще всего выступающего в виде юридического оформления ничем неограниченной государственной власти. Концепция «исключительного положения», допуская экстраординарные полномочия государства, предупреждает, что в таком чрезвычайном положении государство трансформируется в голую силу, или говоря словами Т. Гоббса, становится «левиафаном» - всепоглощающим монстром, способным контролировать тотально общественную жизнь. Только детальное юридическое определение оснований, пределов и полномочий в чрезвычайных условиях может предотвратить превращение государства в машину для насилия и подавления.

Таким образом, критика чрезвычайного правового регулирования проводится на основании двух аргументов:

1. чрезвычайный правовой режим расширяет властные полномочия государственной власти и угрожает нарушением прав и свобод человека и гражданина, установлением авторитарных или тоталитарных режимов;

\footnotetext{
${ }^{8}$ Гессен В.М. Исключительное положение. СПб., 1908

${ }^{9}$ Магазинер Я.М. Чрезвычайно-указное право в России. М., $1911.172 \mathrm{c}$.
} 
2. возможности правового регулирования в экстремальных условиях сведены к минимуму, поскольку предвидеть развитие чрезвычайной ситуации заранее невозможно.

Признавая известную долю истину в такой критике, все-таки аргументы в пользу правового регулирования в чрезвычайных обстоятельствах более весомы.

Во-первых, соображения самосохранения общества и государства вынуждают прибегать к исключительным мерам, вводить ограничение частных интересов в пользу государственных и общественных интересов. Известный правовед Блюнчли еще в XIX в. писал: «Государство есть существо столь высокого порядка, что сохранение его существования, забота о котором составляет первую обязанность правительства, может, в крайнем случае, оправдывать нарушение индивидуальных прав и отступление от обычного порядка. Когда дело идет действительно о спасении государства и когда это спасение невозможно без нарушения существующих прав отдельных лиц или даже целых классов населения, правительство не может и не должно, щадя эти права, обрекать государство на гибель: непреклонно следуя принципу - воля народа есть высший закон, оно должно сделать все, что необходимо для сохранения и спасения государства. Для того, чтобы спасти корабль во время бури, искусный капитан без колебания предоставляет имущество своих пассажиров на произвол бушующих волн; чтобы доставить армии победу в сражении или обеспечить ей благополучное отступление, полководец решается подвергнуть верной гибели отдельные батальоны, если это - единственное к тому средство. Государственный муж, правитель не может поступить иначе в том случае, когда государство является в крайней опасности» ${ }^{10}$.

Во-вторых, мировой опыт показывает не только отрицательные примеры использования чрезвычайного правового режима, но и случаи эффективного применения чрезвычайных мер для восстановления порядка и стабильности в жизни общества (использование спящих полномочий испанским королем в условиях гражданской войны, введение чрезвычайных режимов для устранения последствия природных, техногенных катаклизмов и катастроф).

${ }^{10}$ Bluntschli. Fllgemeines Staatsrecht. Munchen. 1863. P. 112 -113 .
В-третьих, наличие четкой и продуманной правовой основы для деятельности государственных органов в чрезвычайных условиях позволяет минимизировать опасные последствия чрезвычайных мер - авторитаризм, насилие, нарушение прав человека. Совершенно верно на необходимость юридической проработки механизма чрезвычайного положения указывает В.В. Сорокин: «Представляется крайне важным определить те основания, которые правомерно вызывают необходимость объявления чрезвычайного положения. Ограничивать оправданность чрезвычайных акций эфемерной «защитой национальных интересов» либо соображениями восстановления порядка недопустимо. Поскольку морально-этических ограничений государственного насилия явно недостаточно, необходимо наличие конкретных законодательных ограничений - перечень оснований введения чрезвычайного положения должен быть изложен в конституционном законе в исчерпывающем виде» ${ }^{11}$.

В-четвертых, в определенных пределах допустимо прогнозирование чрезвычайных ситуаций и создание систем раннего предупреждения, в том числе юридического содержания. Так, в России и за рубежом давно используется система гражданской обороны - т.е. подготовки населения к возможным чрезвычайным ситуациям.

Таким образом, выбор в пользу чрезвычайного правового регулирования - есть выбор из двух зол. И чрезвычайное право - есть меньшее зло, чем вовсе оставлять внеправовое поле для деятельности государства в экстраординарных обстоятельствах. Вне закона деятельность государства не имеет никаких границ и по определению будет носить насильственный характер. Дореволюционный специалист по полицейскому праву Дерюжинский отмечал: «Для того, чтобы предупредить возможные злоупотребления, закон точно определяет случаи, в которых может быть временно установлен исключительный режим, и те последствия, которыми он сопровождается. Законодательство, составленное обдуманно и с полным спокойствием, имеет несомненное преимущество перед мерами, принимаемыми наскоро в разгар кризиса, под неизбеж-

${ }^{11}$ Сорокин B.B. Теория государства и права переходного периода. - Барнаул.: ОАО «Алтайский полиграфический комбинат», 2007. С. 68. 


\section{Политика и общество 9 (105) • 2013}

ным влиянием событий, вызывающих возбужденное состояние» ${ }^{12}$.

Для того, чтобы избежать такое внеправовое насилие и уберечь общество от насилия заранее необходимо четко определить в законодательстве условия использования чрезвычайного правового регулирования. Так, опыт использования чрезвычайных мер в России начала 1990-х гг. показал, что использование вооруженных сил для разрешения политических конфликтов внутри страны чревато необоснованным насилием и жертвами, не устранением конфликта, а его эскалацией. Кроме того, введение войск на территории Чеченской Республики, Северной Осетии, Ингушетии без объявления чрезвычайного положения и соблюдения процедуры не только обостряло конфликты, но и создавала почву для произвола, злоупотребления полномочиями, применения военной силы к гражданскому населению.

В странах, где проведен в жизнь принцип разделения властей, опасно предоставлять главе государства право на создание чрезвычайного законодательства. Как орган исполнительной власти, глава государства в экстремальной ситуации будет действовать на основании собственных актов. Контроль же главой государства в такой ситуации невозможен. Прав был Н.М. Коркунов, который в конце XIX в. писал о том, что «издание чрезвычайного указа есть, собственно правонарушение, оправдываемое только требованиями необходимости. Устанавливаемые ими меры могут быть по праву установлены только законодательным актом» ${ }^{13}$.

Поэтому целесообразнее было бы то, что принятие чрезвычайного законодательство - есть прерогатива высших законодательных (представительных) органов, которые тем самым ограничивают властные полномочия исполнительной власти и контролируют действия правительства.

Анализ законодательства России и зарубежных стран, научной литературы позволяет сформулировать ряд условий применения чрезвычайного правового регулирования, которые должны быть зафиксированы в нормативно-правовых актах:

- введение чрезвычайных мер должно производиться на основании решения высших органов

12 Дерюжинский В.Ф. Полицейское право. - СПб., 1903. C. 178.

${ }^{13}$ Коркунов Н.М. Указ и закон. Спб., 1894. С. 272. государственной власти в соответствии с юридической процедурой, причем желательно, чтобы чрезвычайный режим устанавливался представительными органами власти или под их контролем;

- для введения чрезвычайного режима должны быть серьезные основания, связанные с угрозой для безопасности общества и государства. Причем проверка наличия таких оснований может быть поручена высшим судебным органам;

- в законе должно быть четко прописаны основания и порядок применения насилия и ограничения прав и свобод человека в условиях чрезвычайного положения;

- в соответствующих нормативно-правовых актах должны быть предусмотрены полномочия, функции и пределы деятельности органов государственной власти, особенно чрезвычайных органов управления;

- законодательно должен быть определен запрет на применение вооруженных сил для разрешения внутренних конфликтов;

- чрезвычайное правовое регулирование должно быть строго ограничено временными и пространственными рамками, которые могут быть изменены при соблюдении должной правовой процедуры;

- чрезвычайные меры должны быть адекватны возникшим обстоятельствам;

- деятельности чрезвычайных органов должна протекать в строгих правовых формах и документально оформляться;

- после отмены чрезвычайных мер может быть проведена проверка правоохранительными и судебными органами законности деятельности государства с изобличением и наказанием виновных лиц.

Таким образом, чрезвычайное правовое регулирование является обоснованной исключительной мерой для преодоления возникших для безопасности общества и государства угроз. Конечно, само чрезвычайное право в своей основе есть нарушение ординарного законодательства и может быть квалифицирована как правонарушение. Но, право на правонарушение чрезвычайной ситуации - вынужденное зло, дающее основу для восстановления порядка и безопасности общества. В этом отношении чрезвычайное правовое регулирование сродни таким институтам как необходимая оборона, крайняя необходимость, обоснованный риск. Во всех этих случаях речь идет об исключении из общих правил 
ради более высокой ценности. Но, при этом всегда сохраняется риск выхода за пределы предоставленных возможностей и полномочий и совершение правонарушения. Но, без такого риска невозможно гарантировать сохранение более высоких ценностей, чем формальное соблюдение закона.

В позитивном праве не только должно содержаться указание на право государственной власти выходить за пределы закона и прибегать к чрезвычайным мерам, но и должны устанавливаться четкие требования к основаниям, условиям, процедуpe, срокам введения чрезвычайного положения и определяться полномочия чрезвычайных органов. В противном случае деятельность государства будет угрожать внеправовыми и насильственными мерами, нарушением гражданских прав, установлением диктатуры.

\section{Библиография:}

1. Лейст О.Э. Сущность права. Проблемы теории и философии права.-М.: Зерцало, 2008.

2. Байтин М.И. Сущность права (современное нормативное правопонимание на грани двух веков). - Саратов.: СГАП, 2001.

3. Сорокин В.В. Понятие и сущность права в русской духовной культуре. - М.: Юрлитинформ, 2007.

4. Кудрявцев В.Н. Правовое поведение: норма и патология.-М.: Наука, 1982.

5. Матио А. Теория чрезвычайных обстоятельств. - M., 1992.

6. Магазинер Я.М. Чрезвычайно-указное право в России. М., 1911.

7. Марченко М.Н. Источники права. - М.: Проспект, 2001.

8. Сорокин В.В.. Теория государства и права переходного периода. - Барнаул.: ОАО «Алтайский полиграфический комбинат», 2007.

9. Венгеров А.Б. Теория государства и права. М.: Юриспруденция, 2000.

10. Алексеев К. П., Першиц А. И. История первобытного общества. М., 1990;

11. Дробышевский С.А. Политическая организация общества и право как явления социальной эволюции. - Красноярск.: КрасГУ, 1995.

12. Гессен В.М. Исключительное положение. СПб., 1908
13. Bluntschli. Fllgemeines Staatsrecht. Munchen. 1863.

14. Дерюжинский В.Ф. Полицейское право. СПб., 1903.

15. Коркунов Н.М. Указ и закон. Спб., 1894.

16. Белковец Л.П. Иностранцы в Советской России (СССР): регулирование правового положения и порядка пребывания (1917 - 1939-е гг.) Первая часть. // NB: Вопросы права и политики. - 2013. - 5. - C. 296 - 350. URL: http://www.e-notabene. $\mathrm{ru} / \mathrm{lr} /$ article_796.html

17. Белковец Л.П. Иностранцы в Советской России (ССС): регулирование правового положения и порядка пребывания (1917 - 1939-е гг.) Вторая часть. // NB: Вопросы права и политики. - 2013. - 6. - C. 220 - 284. URL: http://www.e-notabene. $\mathrm{ru} / \mathrm{lr} /$ article_808.html

\section{References (transliteration):}

1. Leist O.E. Sushchnost' prava. Problemy teorii i filosofii prava.-M.: Zertsalo, 2008.

2. Baitin M.I. Sushchnost' prava (sovremennoe normativnoe pravoponimanie na grani dvukh vekov). - Saratov.: SGAP, 2001.

3. Sorokin V.V. Ponyatie i sushchnost' prava v russkoi dukhovnoi kul'ture. - M.: Yurlitinform, 2007.

4. Kudryavtsev V.N. Pravovoe povedenie: norma i patologiya.-M.: Nauka, 1982.

5. Matio A. Teoriya chrezvychainykh obstoyatel'stv. - M., 1992.

6. Magaziner Ya.M. Chrezvychaino-ukaznoe pravo v Rossii. M., 1911.

7. Marchenko M.N. Istochniki prava. - M.: Prospekt, 2001.

8. Sorokin V.V.. Teoriya gosudarstva i prava perekhodnogo perioda. - Barnaul.: OAO «Altaiskii poligraficheskii kombinat», 2007.

9. Vengerov A.B. Teoriya gosudarstva i prava. - M.: Yurisprudentsiya, 2000.

10. Alekseev K. P., Pershits A. I. Istoriya pervobytnogo obshchestva. M., 1990;

11. Drobyshevskii S.A. Politicheskaya organizatsiya obshchestva i pravo kak yavleniya sotsial'noi evolyutsii. - Krasnoyarsk.: KrasGU, 1995.

12. Gessen V.M. Isklyuchitel'noe polozhenie. SPb., 1908

13. Bluntschli. Fllgemeines Staatsrecht. Munchen. 1863. 
DOI: $10.7256 / 1812-8696.2013 .9 .9482$

При цитировании этой статьи сноска на doi обязательна

\section{Политика и общество 9 (105) • 2013}

14. Deryuzhinskii V.F. Politseiskoe pravo. - SPb., 1903.

15. Korkunov N.M. Ukaz i zakon. Spb., 1894.

16. Belkovets L.P. Inostrantsy $\mathrm{v}$ Sovetskoi Rossii (SSSR): regulirovanie pravovogo polozheniya $\mathrm{i}$ poryadka prebyvaniya (1917 - 1939-e gg.) Pervaya chast'. // NB: Voprosy prava i politiki. -2013.
- 5. - C. 296 - 350. URL: http://www.e-notabene. $\mathrm{ru} / \mathrm{lr} /$ article_796.html

17. Belkovets L.P. Inostrantsy v Sovetskoi Rossii (SSSR): regulirovanie pravovogo polozheniya i poryadka prebyvaniya (1917 - 1939-e gg.) Vtoraya chast'. // NB: Voprosy prava i politiki. -2013. -6. - C. $220-284$. URL: http://www.e-notabene.ru/lr/article_808.html 